\title{
Isothermal and Non-Isothermal Crystallization Kinetics of PVDF and PVDF/PMMA Blends
}

\author{
Jianbin SONG*,Yuan CAI, Bin ZHANG, Lixin TANG, Rongrong SHI, Haiyan SUN, Liang WANG, Yonghuan YAN \\ College of Chemical Engineering and Materials, Nanjing Polytechnic Institute, Nanjing,210048, China
}

*Corresponding Author: Jianbin SONG, E-mail: jianbin1102@163.com

\begin{abstract}
:
Background: poly(vinylidene fluoride) PVDF and PVDF/PMMA blends have been investigated with a focus on the crystal structure, immiscibility and mechanical properties. However, few reports were found on the crystallization behaviors of PVDF and PVDF/PMMA blends, especially on crystallization kinetics. The article is to report the research on isothermal and nonisothermal crystallization kinetics for PVDF and PVDF/PMMA blends using differential scanning calorimetry (DSC). Results: Besides crystallization temperature and isothermal crystallization activation energy, the Avrami equation exponent of PVDF in blends decreased compared with pure PVDF. The nonisothermal crystallization kinetics of PVDF and PVDF/PMMA (70:30) blends were investigated by Ozawa equation, Jeziorny method and crystallization rate constant (CRC) in detail. The nonisothermal crystallization energy of pure PVDF and its blends were determined by the Kissinger and Vyazovkin's method. Conclusion: The nucleation and growth mechanism of PVDF in blends changed compared with pure PVDF. The Ozawa equation is not applicable in nonisothermal crystallization kinetics of PVDF and PVDF/PMMA blends. The decreasing of crystallization ability of PVDF in blends were found and confirmed by CRC and the decline of crystallization rate constant in Jeziorny method. Such is opposite to the results of Kissinger's and Vyazovkin's method, chances are that these two methods were not used to calculate the nonisothermal crystallization activation energy where the nucleation process was influenced.
\end{abstract}

Keywords: PVDF; PMMA; crystallization; isothermal

\section{Introduction}

The investigation of isothermal and non-isothermal crystallization kinetics is very important to ultimate properties of polymer products. This is because many macroscopic properties of polymer largely depend on their crystal structure and spherulite morphology which in turn is determined by the crystallization conditions. So the research in this field is very useful for polymer industry.

PVDF, with excellent resistance to chemistry erosion, high temperature, oxidation and irradiation, especially good piezoelectricity, pyroelectricity, has been extensively studied in recent years ${ }^{[1]}$. Many researchers have done a lot of works centered on the crystal structure, crystallization, grafting and blending ${ }^{[2-6]}$. It has been reported that PVDF could be blended with many polymers and exhibited excellent properties ${ }^{[7-10]}$. Recently, the physical blending of polymer thanks to its convenience and easy processing has been popular in polymer modification fields. PVDF and PMMA within the whole ratio could be miscible by melt blending or by solution blending. The reference ${ }^{[1]}$ has reported that PVDF with $30 \mathrm{wt} \%$ PMMA held good balance of optical properties, solvent resistance, hardness, mechanical strength and weathering resistance, whereas relevant crystallization kinetics data is devoid, which are important meaning to the materials processing.

Therefore, the aim of this article is to obtain more information with respect to the crystallization behaviors of PVDF and PVDF/PMMA (the mass ratio is 70:30) using DSC. The dimethyl sulphoxide (DMSO) solvent was used to dissolve the PVDF and PMMA resin.

\section{Experimental part}

\subsection{Materials and Sample Preparation}

PVDF (FR902), with melt index $10 \mathrm{~g} / \mathrm{min}$, is purchased from Shanghai 3F New Materials Co. Ltd. (China). PMMA resin (HT1000L) is bought from Kuraray Co. Ltd. (Japan).

PVDF and PVDF/PMMA with mass ratio of 70:30 are dissolved in the DMSO solvent at $70^{\circ} \mathrm{C}$, agitated until the completion of dissolving yielding $20 \mathrm{wt} \%$ condensable solutions. The solution was casted on the glass plate, and then dried in a vacuum oven at $80^{\circ} \mathrm{C}$ for $24 \mathrm{~h}$ in order to 
remove the residual DMSO solvent.

\subsection{DSC measurement}

The Perkin-Elmer Diamond apparatus are used to investigate the crystallization kinetics of PVDF and PVDF/ PMMA blends. The weights of samples are 3 4 mg to the transmission of quantity of heat. All the DSC runs are performed in the nitrogen atmosphere.

For isothermal crystallization process, at first, the samples are quickly heated to $210^{\circ} \mathrm{C}$ at a heating rate of $150^{\circ} \mathrm{C} / \mathrm{min}$ in DSC, held for $5 \mathrm{~min}$ to eliminate thermal history, and then quickly cooled to designated temperature which ranged from $159^{\circ} \mathrm{C}$ to $155^{\circ} \mathrm{C}$ at intervals of $1^{\circ} \mathrm{C}$ for PVDF and from $147^{\circ} \mathrm{C}$ to $143^{\circ} \mathrm{C}$ at intervals of $1^{\circ} \mathrm{C}$ for PVDF/PMMA blends, and maintained until the completion of crystallization. In the nonisothermal crystallization the PVDF and PVDF/PMMA blends, samples are heated to $210^{\circ} \mathrm{C}$, and then cooled to room temperature at cooling rate of $2.5^{\circ} \mathrm{C} / \mathrm{min}, 5^{\circ} \mathrm{C} / \mathrm{min}, 10^{\circ} \mathrm{C} / \mathrm{min}, 20^{\circ} \mathrm{C} / \mathrm{min}$ and $40^{\circ} \mathrm{C} /$ min, respectively.

\section{Results and Discussion}

\subsection{Avrami Equation Analysis of Isothermal Crystallization}

The macroscopic isothermal crystallization kinetics are usually described in terms of the Avrami equation ${ }^{[12,13]}$, which has been successfully applied in many polymer systems:

$$
X(t)=1-\exp \left(-k t^{n}\right)
$$

This equation may be rewritten further, $\ln (-\ln (1-X(t)))=\ln k+n \ln t$

Where $\mathrm{X}(\mathrm{t})$ is relative crystallinity at time $\mathrm{t}, n$ represents the Avrami exponent that is correlated to the crystallization mechanism and $k$ is overall crystallization rate constant. According to Eq. 2 we can obtain the Avrami exponent and crystallization rate constant from the slope and interception of plots of $(-\ln (1-X(t)))$ versus $\ln t$ at various crystallization temperatures (shown in figure 1 and 2 ).

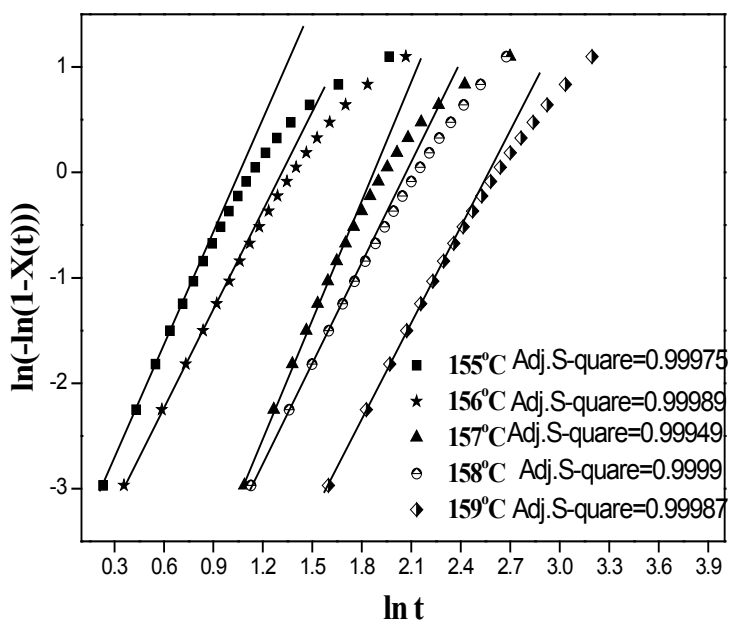

Figure 1 The plots of $\ln (-\ln (1-\mathrm{X}(\mathrm{t})))$ and $\ln \mathrm{t}$ for PVDF at various crystallization temperature $T_{c}$

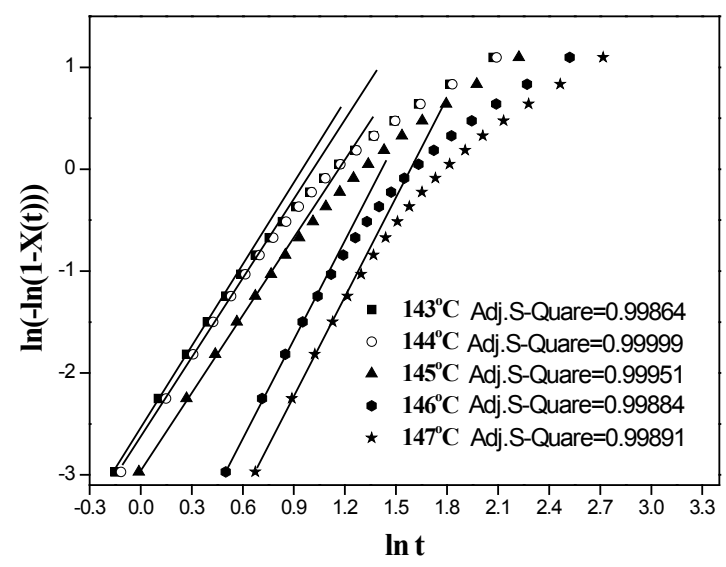

Figure 2 The plots of $\ln (-\ln (1-\mathrm{X}(\mathrm{t})))$ and $\ln \mathrm{t}$ for PVDF/ PMMA blends at various crystallization temperature $\mathrm{T}_{\mathrm{c}}$

Obviously, in figure 1 for PVDF and 2 for PVDF/ PMMA blends, each curve exhibited a beeline at preliminary crystallization which meant the experimental data agreed well with the Avrami equation at low relative crystallinity, and at later crystallization the curves showed a little deviation due to the impingement of spherulites. By fitting to the linear portion at preliminary crystallization of every curve, the Avrami parameters $n$ and crystallization rate constant $k$ can be obtained and the results are shown in Table 1.

Table 1 The isothermal crystallization kinetics parameters for PVDF and PVDF/PMMA blends

\begin{tabular}{cccccc}
\hline & $\mathrm{T}_{\mathrm{c}}\left({ }^{\circ} \mathrm{C}\right)$ & $\mathrm{n}$ & $\mathrm{k}$ & $\begin{array}{c}\mathrm{t}_{1 / 2} \\
(\mathrm{~min})\end{array}$ & $\begin{array}{c}\mathrm{t}_{\max } \\
(\mathrm{min})\end{array}$ \\
\hline pure & 155 & 3.56 & $2.27 \times 10^{-2}$ & 2.61 & 2.64 \\
PVDF & 156 & 3.04 & $1.75 \times 10^{-2}$ & 3.36 & 3.32 \\
& 158 & 3.85 & $7.95 \times 10^{-1}$ & 5.82 & 5.90 \\
& 159 & 3.09 & $1.575 \times 10^{-3}$ & 7.16 & 7.11 \\
& 143 & 2.62 & $7.83 \times 10^{-2}$ & 2.30 & 2.20 \\
PVDF/ & 144 & 2.66 & $7.08 \times 10^{-2}$ & 2.36 & 2.27 \\
PMMA & 145 & 2.51 & $5.33 \times 10^{-2}$ & 2.78 & 2.63 \\
& 146 & 3.15 & $1.10 \times 10^{-2}$ & 3.74 & 3.71 \\
& 147 & 3.13 & $6.437 \times 10^{-3}$ & 4.46 & 4.43 \\
\hline
\end{tabular}

Another two important kinetics parameters is halftime of crystallization $t_{1 / 2}$ and $t_{\max } \cdot t_{1 / 2}$ is defined as the time at which the crystallization is $50 \%$ complete, is determined by

$t_{1 / 2}=\left(\frac{\ln 2}{k}\right)^{1 / n}$

$t_{\text {max }}$ represents the maximum crystallization rate corresponds to the point at which $\mathrm{dQ}(\mathrm{t}) / \mathrm{dt}=0$, with $\mathrm{Q}(\mathrm{t})$ being the heat-flow rate. $t_{\max }$ can be calculated by the Avrami equation, as follows:

$t_{\max }=\left(\frac{n-1}{n k}\right)^{1 / n}$

The $t_{1 / 2}$ and $t_{\max }$ may be used to characterize the 
crystallization rate, which increases as crystallization temperature increases (in Tab 1). It was interesting that the change extent of $t_{1 / 2}$ or $t_{\max }$ for pure PVDF was larger than that for PVDF in PVDF/PMMA blends, which is correlated to higher crystallization temperature of pure PVDF. At the same time this also suggested that PVDF crystallization was more sensitive to temperature changes than PVDF in blends.

From Tab 1 we can also see that after PVDF blending with PMMA the crystallization temperature of PVDF shifted prominently toward to the lower temperature. This indicated that the PVDF crystallization ability turned weak since the movement of PVDF molecular chains were limited by more PMMA. In Tab 1 the Avrami exponents for pure PVDF changed from 3.04 to 3.85 and from 2.51 to 3.15 for PVDF in blends. This indicated that the nucleation and growth mechanism have change from threedimensional growth to two-dimensional growth. Reference ${ }^{[14]}$ has reported that the noncrystalline component would influence nucleation mechanism and growth geometry of crystalline component.

\subsection{Isothermal Crystallization Activation Energy $(\Delta E)$}

The isothermal crystallization activation energy $\Delta E$ is determined by the Arrhenius equation ${ }^{[15]}$, which presumes that the isothermal crystallization process of polymer is to be thermally activated,

$$
\begin{aligned}
& k^{1 / n}=k_{0} \exp \left(-\frac{\Delta E}{R T_{c}}\right) \\
& \frac{\ln k}{n}=\ln k_{0}-\frac{\Delta E}{R T_{c}}
\end{aligned}
$$

Where $k$ is the crystallization rate constant, $\mathrm{n}$ the Avrami exponent, $\mathrm{k}_{0}$ is the temperature-independent preexponential factor, $\mathrm{T}_{\mathrm{c}}$ is the crystallization temperature, $\mathrm{R}$ is the gas constant and $\Delta E$ is isothermal crystallization activation energy.

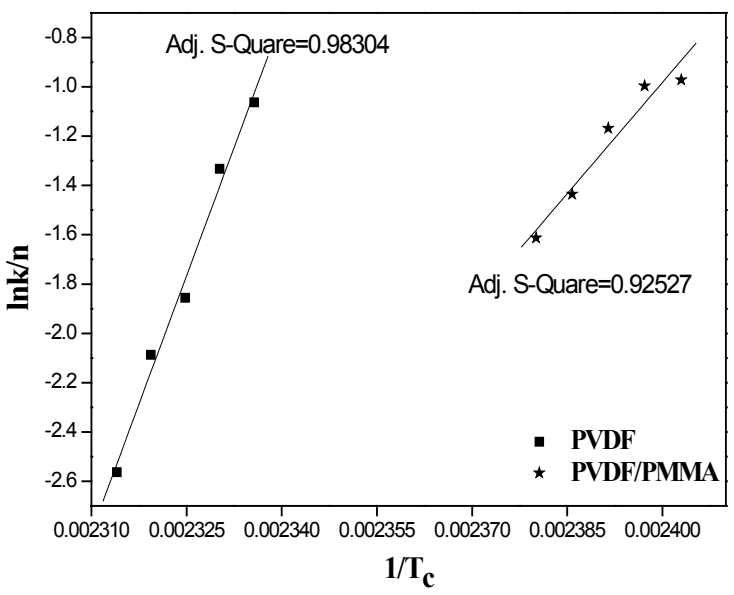

Figure 3 The isothermal crystallization activation energy $\triangle \mathrm{E}$ for PVDF and PVDF/PMMA blends determined by the plots of $\operatorname{lnk} / \mathrm{n}$ and $1 / \mathrm{T}$ 。

By fitting the plots of $\frac{\ln k}{n}$ versus $\frac{1}{T_{c}}$ (shown in figure 3), the isothermal crystallization activation energy $\triangle E$ for pure PVDF and PVDF in PVDF/PMMA blends are determined to be $-577.6 \mathrm{~kJ} / \mathrm{mol}$ and $-250.0 \mathrm{~kJ} / \mathrm{mol}$, respectively. After PVDF blending with PMMA the isothermal crystallization activation energy dramatically decreased, but it must be noted that the values of $\Delta E$ were not applied to elucidate difficulty extent of crystallization in the present experiments owing to the difference of crystallization temperature. In light of the Eq. 5 we know that PVDF with higher $\Delta E$ will be more sensitive to temperature variation than PVDF in blends with lower $\Delta E$ during nonisothermal crystallization process. This accorded with the changes of $t_{1 / 2}$ or $t_{\max }$ in Avrami equation.

\subsection{Ozawa Equation of Nonisothermal Crystallization}

In order to apply the Avrami equation to the nonisothermal crystallization process, Ozawa ${ }^{[16]}$ proposed a method which assumes the polymer system cooled at a constant rate and the Ozawa exponent $\mathrm{m}$ is independent on temperature, which can be prescribed in the following form:

$1-X(T)=\exp \left[-P(T) / \phi^{m}\right]$

$\log [-\ln (1-X(T))]=\log P(T)-m \log \phi$

Where $\mathrm{X}(\mathrm{T})$ is relative degree of crystallinity at crystallization temperature $\mathrm{T}, \mathrm{m}$ the Ozawa exponent, related to the nucleation mechanism and growth geometry, $\mathrm{P}(\mathrm{T})$ is the cooling function of nonisothermal crystallization. By calculating the slope and intercept of $\log [-\ln (1-X(T))]$ versus $\log \phi$ we can easily the values of $\mathrm{m}$ and $\mathrm{P}(\mathrm{T})$. Figure 4 and 5 showed the plots of $\log [-\ln (1-X(T))]$ and $\log \phi$ for PVDF and PVDF/PMMA blends at different crystallization temperature. From the two figures we know that the $\log [-\ln (1-X(T))]$ present curves with $\log \phi$, instead of straight line, and the Ozawa exponents also varied with crystallization temperature. The results suggested that the Ozawa equation was not adaptive to analyze the nonisothermal crystallization behaviors of PVDF and its blends due to ignoring the seconding crystallization.

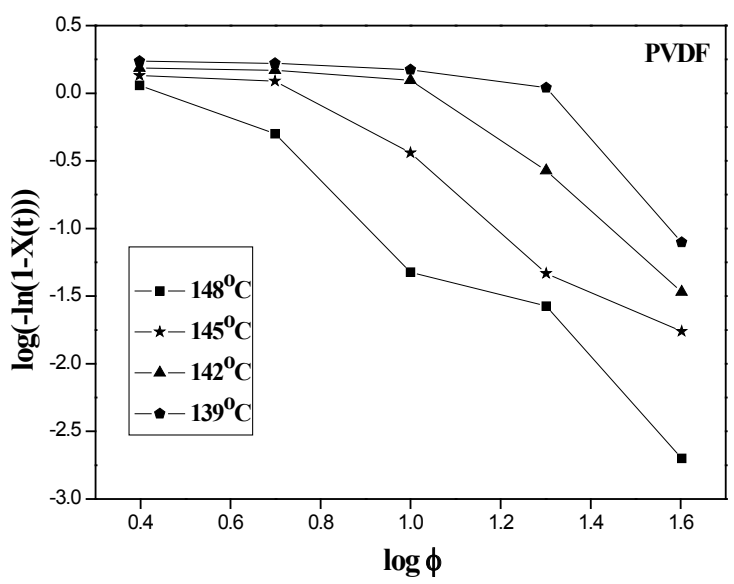

Figure 4 The nonisothermal crystallization of PVDF analyzed by the Ozawa equation 


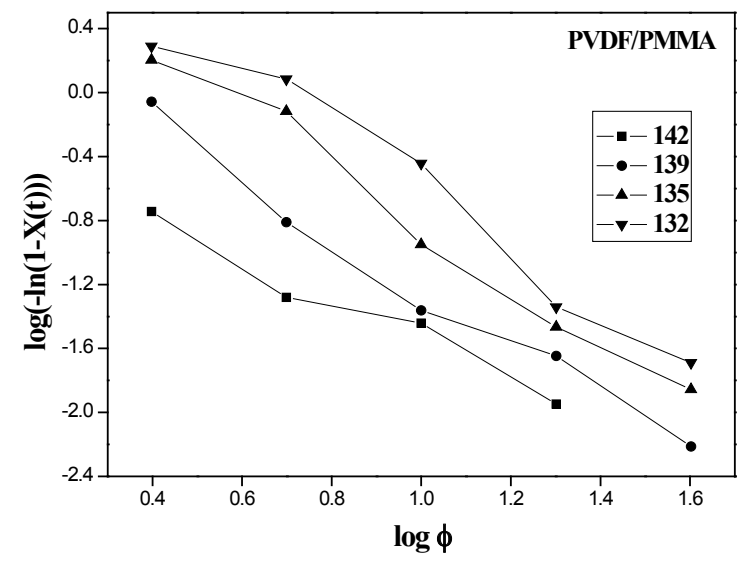

Figure 5 The nonisothermal crystallization of PVDF analyzed by the Ozawa equation

\subsection{The Avrami Equation Modified by Jeziorny}

Mandelkern $[17,18]$ proposed that the nonisothermal crystallization kinetics could be described by the Avrami equation, as follows:

$\log \{-\ln [1-X(t)]\}=n \log t+\log Z_{t}$

Where $Z_{t}$ is the crystallization rate constant. Considering the effect of cooling or heating rate, Jeziorny ${ }^{[19]}$ assumed $\phi$ to be constant or approximately constant.

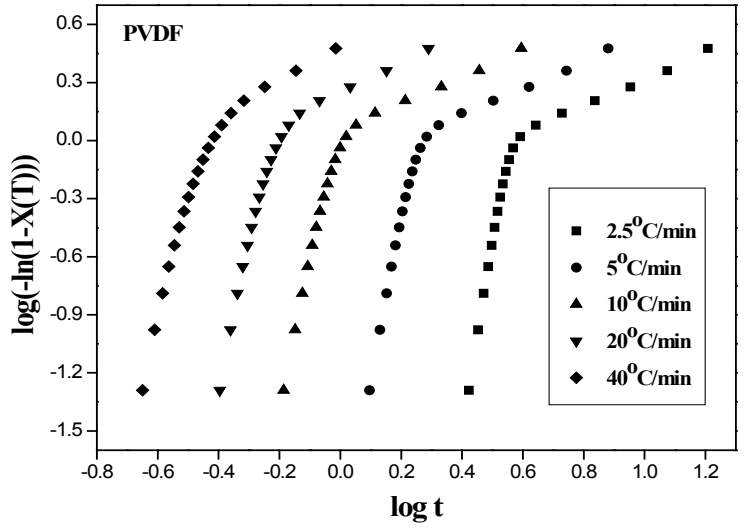

Figure 6 The plots of $\log (-\ln (1-\mathrm{X}(\mathrm{T})))$ and $\log \mathrm{t}$ for PVDF at various cooling rate
The final form of the rate parameter $\left(Z_{c}\right)$, characterizing the nonisothermal crystallization kinetics is given as follows:

$\log Z_{c}=\frac{\log Z_{t}}{\phi}$

Figure 6 and 7 showed the plots of $\log \{-\ln [1-X(t)]\}$ versus $\log \mathrm{t}$ for PVDF and PVDF/PMMA blends at various cooling rate. The values of $n$ and $Z_{c}$ could be obtained from the slope and intercepts, respectively, the results were exhibited in Tab 2. Similar to isothermal crystallization the whole nonisothermal crystallization process may be also divided into two stages: primary and secondary crystallization stages. Dissimilarly, whether in PVDF or PVDF/PMMA blends the Avrami exponent of primary crystallization stage far surpassed 3 at various cooling rate, which hinted spherulite nucleation and growth is very complicated. From Tab 2, we can see that at the same cooling rate the crystallization temperature and the crystallization rate constant of PVDF in blends were lower than that of pure PVDF, which implied the addition of PMMA weaken crystallization ability of PVDF. This is possible attributed to the two reasons: firstly, excess PMMA molecules must inhibit the movement of PVDF molecules during crystallization process. Secondly, the decrease of the concentration of PVDF molecules in blends at unit volume should not be ignored.

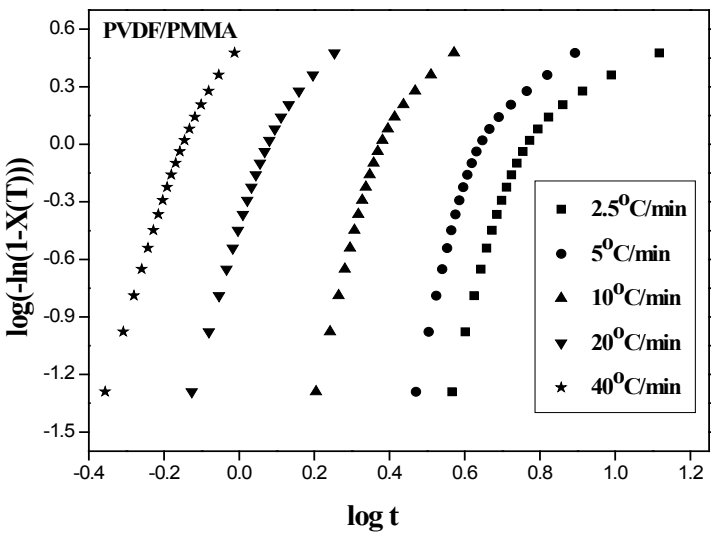

Figure 7 The plots of $\log (-\ln (1-\mathrm{X}(\mathrm{T})))$ and $\log \mathrm{t}$ for PVDF/PMMA blends at various cooling rate

Table 2 The nonisothermal crystallization kinetics parameters for PVDF and PVDF/PMMA blends

\begin{tabular}{|c|c|c|c|c|c|c|}
\hline & \multirow{2}{*}{$\begin{array}{c}\Phi \\
\left({ }^{\circ} \mathrm{C} / \mathrm{MIN}\right)\end{array}$} & \multirow{2}{*}{$\begin{array}{c}\mathrm{T}_{\mathrm{c}} \\
\left({ }^{\circ} \mathrm{C}\right)\end{array}$} & \multicolumn{2}{|c|}{$\begin{array}{c}\text { Primary } \\
\text { Crystallization Stage }\end{array}$} & \multicolumn{2}{|c|}{$\begin{array}{c}\text { Secondary } \\
\text { Crystallization Stage }\end{array}$} \\
\hline & & & $\mathrm{n}_{1}$ & $\mathrm{Z}_{\mathrm{cl}}$ & $\mathrm{n}_{2}$ & $Z_{c^{2}}$ \\
\hline \multirow{5}{*}{ PVDF } & 2.5 & 150 & 9.6 & $7.3 \times 10^{-3}$ & 0.64 & 0.74 \\
\hline & 5 & 148 & 8.1 & 0.39 & 0.66 & 0.94 \\
\hline & 10 & 145 & 7.9 & 1.04 & 0.69 & 1.01 \\
\hline & 20 & 141 & 7.7 & 1.23 & 0.71 & 1.03 \\
\hline & 40 & 137 & 6.8 & 1.20 & 0.88 & 1.09 \\
\hline \multirow{5}{*}{$\begin{array}{l}\text { PVDF/ } \\
\text { PMMA }\end{array}$} & 2.5 & 141 & 7.7 & $5.5 \times 10^{-3}$ & 1.2 & 0.46 \\
\hline & 5 & 137 & 8.7 & 0.085 & 1.6 & 0.64 \\
\hline & 10 & 131 & 8.2 & 0.51 & 2.0 & 0.86 \\
\hline & 20 & 124 & 6.8 & 0.96 & 2.2 & 0.99 \\
\hline & 40 & 115 & 6.5 & 1.1 & 3.0 & 1.03 \\
\hline
\end{tabular}




\subsection{Crystallization Rate Coefficient (CRC)}

Khanna ${ }^{[20]}$ put forwarded a new parameter to describe crystallization ability, "crystallization rate coefficient $C R C=\Delta \phi / \Delta T_{c} " \phi \quad$ is the cooling rate and $\mathrm{T}_{c}$ the crystallization peaks temperature. The values of $\mathrm{T}_{c}$ at various $\Phi$ are exhibited in Tab 2. Here, the larger the values of CRC, the stronger the ability of polymers crystallization is. In the present works, we obtain the values of CRC for PVDF and PVDF/PMMA by fitting cooling rate $\phi$ versus crystallization peaks temperature $T_{c}$ (shown in figure 8 ). In evidence, the slope of PVDF plots is higher than that of PVDF/PMMA blends, which suggested that crystallization ability of PVDF is weakened after blending with PMMA. This result is consistent with the outcomes of Jeziorny method. The CRC values of PVDF and PVDF/PMMA are $166 \mathrm{~h}^{-1}$ and $87 \mathrm{~h}^{-1}$, respectively. The CRC of PVDF $\left(166 \mathrm{~h}^{-1}\right)$ is very bigger among semi-crystalline polymers, which approaches to the PTFE, far above PE, nylon 66, nylon 46, PET, etc. however, when blending with PMMA the CRC of

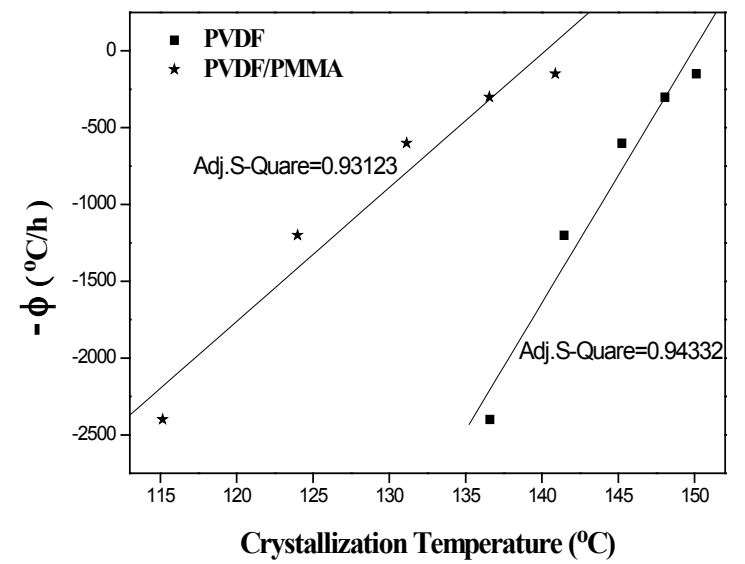

Figure 8 The crystallization rate constant CRC for PVDF and PVDF/PMMA blends at cooling process

3.7 Activation Energy of non-Isothermal Crystallization Proposed by Vyazovkin

Vyazovkin ${ }^{[22]}$ believed that the Kissinger's method is not used to determined the nonisothermal crystallization activation energy on cooling from melt, therefore he proposed and adopted Friedman's ${ }^{[23]}$ equation to calculate the nonisothermal crystallization activation energy $\Delta E$, as follows:

$\ln \left[\frac{d X(T)}{d t}\right]=\ln [A f(X(T))]-\frac{\Delta E}{R T}$

Where $\mathrm{X}(\mathrm{T})$ is the relative crystallinity, $\mathrm{t}$ is the time, $\mathrm{A}$ is the pre-exponential factor, and $f(X(T)$ is the crystallization model. At a certain relative crystallinity, $\mathrm{X}(\mathrm{T})$, the slope of the plot of $\ln [\mathrm{dX}(\mathrm{T}) / \mathrm{dt}]$ versus $1 / \mathrm{T}$ was used to measure $\Delta E$, which displayed in figure 10 . The application of this method to nonisothermal crystallization activation energy yields crystallinity-dependent activation energy. the $\Delta E$ of pure PVDF firstly decreased with relative crystallinity increasing, when dropped to minimum value at $60 \%$ relative crystallinity, $\Delta E$ increase suddenly above
PVDF dramatically decreased to $87 \mathrm{~h}^{-1}$, which is close to the CRC of nylon 46 and nylon $66^{[15]}$.

\subsection{Activation Energy of Non-Isothermal Crystallization}

Considering the changes in the crystallization peak temperature with the cooling rate $\phi$, we can derive $\Delta E$ for non-isothermal crystallization by the Kissinger method ${ }^{[21]}$ $\frac{d\left[\ln \left(\phi / T_{c}^{2}\right)\right]}{d\left(1 / T_{c}\right)}=-\frac{\Delta E}{R}$

Where $\mathrm{T}_{\mathrm{c}}$ is the crystallization peaks temperature; $\phi$ is the cooling rate; $\mathrm{R}$ is the gas constant; $\Delta E$ nonisothermal crystallization activation energy. The plots of $\ln \left(\phi / T_{c}^{2}\right)$ and $\Delta E$ were shown in figure 9. The values of $\Delta E$ of PVDF and PVDF/PMMA blends were determined to be $295.3 \mathrm{~kJ} /$ mol and $148.1 \mathrm{~kJ} / \mathrm{mol}$ through fitting the linear parts, respectively, the nonisothermal crystallization activation energy $\Delta E$ did not become bigger but smaller. The reason will be discussed in next section.

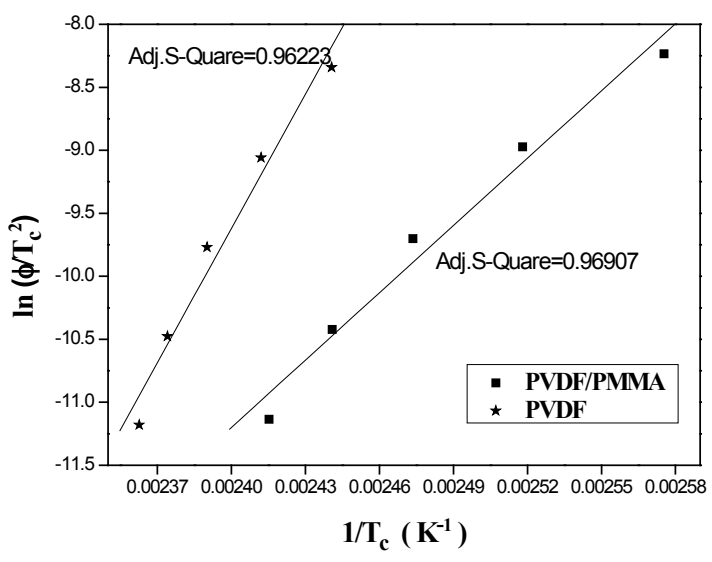

Figure 9 the nonisothermal crystallization activation energy determined by Kissinger method for PVDF and PVDF/PMMA blends

$60 \%$ relative crystallinity. The changing trend for $\Delta E$ in pure PVD proved that at early crystallization stage the polymer system the crystallization rate increase rapidly with crystallization time prolonging, but crystallization rate is slow due to the spherulite impingement and the reduction of crystallizable molecules at later crystallization stage, therefore the nonisothermal crystallization activation $\Delta E$ increases. Conversely, the activation energy $\Delta E$ for PVDF in PVDF/PMMA blends by and large does not change on the whole relative crystallinity ranges and keeps at $123 \mathrm{~kJ} /$ mol or so, this is possibly correlated to PVDF diluted and dispersed by PMMA.

Note that in terms of CRC and Jeziorny method the PVDF in PVDF/PMMA blends crystallization should be weakened compared with pure PVDF, that is, the nonisothermal crystallization activation energy $\Delta E$ would increased after PVDF blended with PMMA. However, both the Kissinger's method and Vyazovkin's method showed the $\Delta E$ decreased after blending. Such phenomenon, some researchers considered, the Kissinger method is not suited in treating with nonisothermal crystallization on cooling 
from melt ${ }^{[22]}$, the others ${ }^{[24]}$ figured the Kissinger method was not used in which the spherulite nucleation and growth were affected, in our situation the authors considered, similar to Kissinger method, the Vyazovkin's method was also not appropriate where spherulite nucleation and growth were affected.

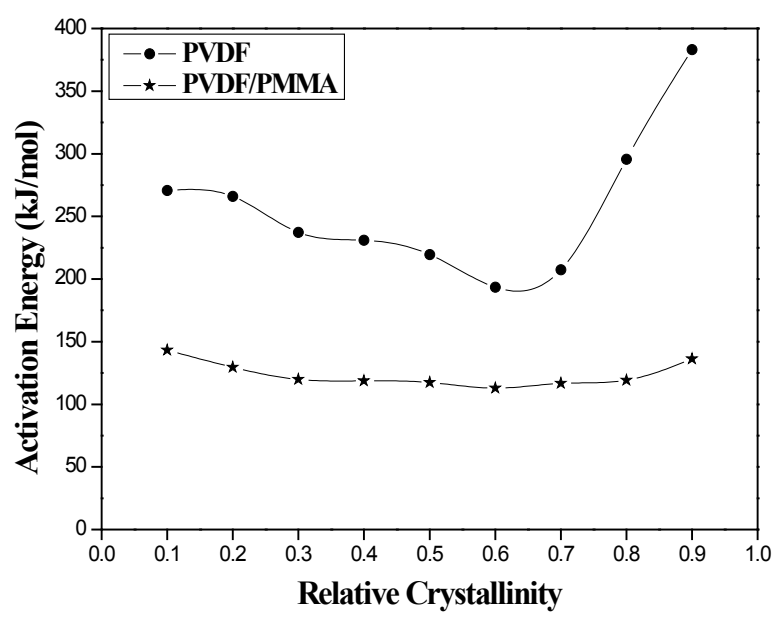

Figure 10 The nonisothemal crystallization activation energy as a function of relative crystallinity for PVDF and PVDF/PMMA blends on the basis of Vyazovkin's advice

\section{Conclusions}

Using the DSC we studied the isothermal and nonisothermal crystallization kinetics of PVDF and PVDF/ PMMA blends with mass ratio 70:30, which were prepared by dissolving in DMSO. The isothermal crystallization kinetics were analyzed by the Avrami equation, and the results have indicated PVDF spherulite in blends have changed into two-dimensional growth, at the same time the decrease of crystallization temperature was found. The isothermal crystallization activation energy in PVDF was determined to be $-577.6 \mathrm{~kJ} / \mathrm{mol}$, higher than that PVDF in blends $(-250.0 \mathrm{~kJ} / \mathrm{mol})$. At the same cooling rate the PVDF/PMMA blends represented lower crystallization peaks temperature compared with PVDF, what's more the crystallization rate constants $Z_{c}$ for PVDF at primary or secondary crystallization stage were higher than that for blends. The crystallization rate constant (CRC) was measured to be $166 \mathrm{~h}^{-1}$ OF PVDF and $87 \mathrm{~h}^{-1}$ of PVDF in blends, respectively. The results of $Z_{c}$ and CRC implied that PVDF crystallization ability in PVDF/PMMA blends weakened under nonisothermal crystallization conditions. It was found that the Ozawa equation was not used to investigate nonisothermal crystallization kinetics for PVDF and PVDF/PMMA blends. The Kissinger method and Vyazovkin's method were not proper to calculate nonisothermal crystallization activation energy in which the nucleation was influenced.

Acknowledgements: This work was financially supported by Start Fund For High Level Talents of Nanjing Polytechnic Institute (China).

\section{References}

[1] Esterly DM and Love BJ. J Polym Sci Part B: Polym Phys 42:91 (2004).

[2] Zhang GZ, Kitamura T, Yoshida $\mathrm{H}$ and Kawai T, J Therm Anal Calorim 69:939 (2002).

[3] Gregorio JR and Cestari M, J Polym Sci Part B: Polym Phys 32:859 (1994).

[4] Moussaif M, Pagnoulle C, Riga J and Jerome R, Polymer 41:3391 (2000).

[5] Li G., Zhu B, Zhang C and Xu Y, J Appl Polym Sci 107:2109 (2008).

[6] Holmberg S, Nasman J and Undholm F, Polym Advan Technol 9:121 (1996).

[7] Nishi T and Wang TT, Macromolecules 8:909 (1975).

[8] Kader MA, Kwak SK, Kang SL, Ahn JH and Nah C, Polym Int 57:1199 (2008).

[9] Pramoda K, Mohamed A, Phang IY and Liu TX, Polym Int 54:226 (2005).

[10] Benedetti E, Catanorchi S, Alessio AD and Vergamini P, Polym Int 45:373 (1998).

[11] Lin S, Argasinski K, In:Hougham G, Cassidy Pe, Johns K, Davidson T, (Eds). Fluoropolymer Alloys Performance Optimization of Pvdf Alloys, Plenum Press, New York, P121 (1999).

[12] Avrami MJ, Chem Phys 7:1103 (1939).

[13] Avrami MJ, Chem Phy 8:212 (1939).

[14] Chiu HJ, J Polym Res 9:169 (2002).

[15] Yin JH and Mo ZS, Modern Polymer Physics, Science Press, Beijing, 2001

[16] Ozawa T, Polymer 12:150 (1971).

[17] Fava RA, Methods of Experimental Physics Academic New York, 1980, 16.

[18] Zhang QX, Zhang ZH, Zhang HF and Mo ZS, J Polym. Sci Part B: Polym Phys 40:1790 (2002).

[19] Jeziomy A, Polymer 19:1142 (1978).

[20] Kissinger HE, J Res Natl Bur Stand 57:217 (1956).

[21] Vyazovkin S, Macromol Rapid Comm 23:771 (2002).

[22] Friedman H, J Polym Sci Part C 6:183 (1964).

[23] Liu MY, Zhao QX, Wang YD, Zhang CG, Mo ZS and Cao SK, Polymer 44:2537 (2003). 